\title{
Developing The Personal Data Protection In The European Union: A Consumer-Oriented Approach - The Romanian Experience
}

Calin Veghes, (Email: c_veghes@yahoo.com), Academy of Economic Studies in Bucharest, Romania

\begin{abstract}
Protection of personal data represents a relatively recent concern for all the entities - consumers, organizations and public institutions - involved in the development of the direct marketing industry and the overall Romanian market. Noteworthy growth of the direct marketing campaigns, increase in the consumer demands and expectations and the background provided by the country's adhesion to the European Union, have determined a strong necessity to build up a legal framework for protection of the personal data. Important steps have been made when laws no. 677 (on the protection of the personal data in terms of their processing and free circulation - 2001), no. 506 (on the processing of personal data and protection of privacy in the electronic communications sector - 2004) and no. 102 (regarding the setting up, organization and functioning of the National Supervisory Authority for Personal Data Processing - 2005) have been issued. Adoption of the Directive no. 95/46/EC has connected Romanian and European Union legal framework of the personal data protection. Enforcement of the existing legal background has revealed several problems that have affected activities conducted mainly by the direct marketing and marketing research companies. Relatively unclear definition of the content of personal data to be protected appeared to be one of the most important. From this point, at least the following questions should be answered:

- what is the specific meaning of the "personal" data? What data is "personal" and must be protected through dedicated laws and regulations?

- $\quad$ are public initiatives best ways and public institutions sole entities to handle the development of an effective legal background for the personal data protection?

- how important is the voice of the consumers in the process of development of a regulatory environment in this area? Should those to be protected represent the main source of initiating and building the related legal framework?

An exploratory survey on a sample including 96 Romanian urban consumers aged 18 to 45 has been conducted aiming to provide information on the: importance of the data protection for the consumers, main characteristics of the data protection legal environment (area of protection, public-private, respectively national-international relationships in terms of the data protection, need for national or international laws and regulations), content of the personal data to be protected by a more precisely defined object of the law, consumer preferences regarding the opt-in and opt-out mechanisms, knowledge associated to the legal rights of consumers related to the personal data protection as they are granted through the existing law, major risks associated with the absence or improper personal data protection mechanisms, consumers' exposure to the personal communication media, preferences for personal sources of information and perceived importance of personalization as potential factors to be considered for the development of the personal data protection legal framework, opportunity to develop and implement a Robinson list.

Results of the survey may serve as a starting point for a future research conducted at the level of a national representative sample and the Romanian experience may be considered for the upcoming effort to develop a legal framework of the personal data protection in the European Union based on the consumers' views, needs and expectations.
\end{abstract}

\section{INTRODUCTION}

irst laws regarding the protection of the personal data have been issued in Sweden - the Data
Protection Act (1973) and United States - the Privacy Act (1974) and their implementation has been
motivated mainly by the evolutions in the field of the public-owned data management (Stephens, 
1998). Increases in the amount of data to be collected, processed and used, new information and communication technologies employed to conduct all the related activities, necessity to protect the consumer rights having as background the context provided by the human rights have imposed public authorities to consider and find solutions to create and put into practice a proper legal environment of the personal data protection. Several generations of data protection norms have been built to ensure a better protection and the process continues (Jóri, 2007).

In Europe, the first steps have been made through the European Convention for the Protection of Human Rights and Fundamental Freedoms (1950) that specified the right to respect for private and family life (article 8). The Council of Europe has elaborated the Convention for the Protection of Individuals with regard to the Automatic Processing of the Personal Data (1981) that has defined basic principles of the fair and lawful data collection and use. In order to implement the basic principles regarding the personal data protection, Council of Europe has adopted several recommendations dealing with medical databanks (1981), scientific and other statistical research (1983), direct marketing (1985), social security (1986), police records (1987), employment data (1989), financial payments and related transactions (1990), communication of data to third persons by public institutions (1991), protection of personal data in the field of telecommunications, in particular telephone services (1995), protection of medical and genetic data (1997), protection of personal data collected and processed for statistical purposes (1997) and protection of privacy on the Internet (1999).

The Organization for Economic Co-operation and Development has issued (1980) a set of guidelines on the protection of privacy and trans-border flows of personal data that have been globally accepted and are seen as common denominator for the European Union and United States. Their basic principles refer to:

- $\quad$ collection limitation: any personal data should be obtained by lawful and fair means and, where appropriate, with the knowledge or consent of the data subject;

- data quality: personal data should be relevant to the purposes for which they are to be used, and, to the extent necessary for those purposes, should be accurate, complete and kept up-to-date;

- $\quad$ purpose specification: purposes for which personal data are collected should be specified at the time of data collection and the subsequent use limited to the fulfillment of those purposes;

- $\quad$ use limitation: personal data should not be disclosed, made available or otherwise used for purposes other than those specified excepting with the consent of the data subject or by the authority of law;

- $\quad$ security safeguards: personal data should be protected by reasonable security safeguards against such risks as loss or unauthorized access, destruction, use, modification or disclosure;

- $\quad$ openness: a general policy of openness about developments, practices and policies with respect to personal data and the identity and usual residence of the data controller should be implemented;

- individual participation: individuals should have the right in their relationship with data controllers concerning the storage, access and any changes to their personal data;

- $\quad$ accountability: data controllers should be accountable for complying with principles stated above.

European Convention and the OECD Guidelines have provided the background for the later issuing of the Directive 95/46/EC on the protection of individuals with regard to the processing of personal data and on the free movement of such data. The directive has been basically adopted and its provisions were transposed by all the European Union member states.

Direct marketing and marketing research industries have been among the areas significantly affected by the implementation of the personal data directive. Analyzing the context of personal data protection development within the European Union based on this directive, Jack Safell has found (2007) that European personal data protection law balances between rights of the data subjects and needs of data controllers, there are different approaches (statutory, administrative etc.) at national level in applying personal data protection law and the member states still play a large role in defining approach to data processing.

In spite of the reference legal framework provided for all the member states, Directive left unsolved at least two essential operational and conceptual aspects. From an operational perspective, Directive asks the organizations to obtain the consumers consent in order to collect and use their personal data. From a conceptual perspective, 
Directive leaves the content of the personal data insufficiently defined. Major effects of these are to be seen in the increase of direct marketing costs (due to the opt-in mechanism to be included) as well as in the potential abuses made both by the organizations willing to conduct direct marketing campaigns and the public authority during the enforcement of the personal data protection law.

Lucas Bergkamp (2002) has observed that Directive has not defined privacy and consequently created a troubling institutional framework in terms of the personal data protection. He has identified that solving the privacy issue implies a "classical choice of political philosophy": option between relying on the market, respectively on the government to produce and deliver privacy. Bergkamp suggests that markets provide flexibility and have the ability to accommodate the diverging demands while government creates laws imposing one-fits-all solutions focused merely on formal solving of the problem.

Privacy of consumers became an extremely important matter to be taken into consideration during planning and implementation of direct marketing campaigns. Stone and Jacobs (2001) quoted the study of Mary J. Culnan (University of Georgetown) showing that consumers may understand and accept collection and use of their personal data when conducted appropriately. Consumers are concerned by the potential misuses of the data for other purposes than initially announced or by third and/or unauthorized parties and perceive frauds committed against them, identity theft and unsolicited communication as major risks. Study revealed that when consumers have the opportunity to opt-out from a list/database they become less worried about the status of their personal data and privacy. One of the solutions for direct marketers has been suggested by Seth Godin through the definition of permission marketing (Godin, 1999) as a marketing activity centered on obtaining customer consent to receive information from a company.

In order to be appropriately protected, privacy and content of the personal data must be clearly and specifically defined [1]. Development of the related protection laws and regulations should be conducted with the participation of all the parties involved - consumers, organizations and public entities. Paper provides a set of exploratory data [2] regarding the opinion of the Romanian consumers as data subjects about these matters.

\section{IMPORTANCE OF THE DATA PROTECTION}

First objective of the research has been to determine the level of importance of personal data protection matter for the investigated consumers. In this respect, $90.7 \%$ have appreciated personal data protection as being "important" $(49.0 \%)$ or "very important" $(41.7 \%)$ to them. It is to be expected this result to be lower at a level of representative national sample as the concern for personal data protection could be less important in the rural areas. These weights are relatively similar to the results provided by the Special Eurobarometer 196 on Data Protection conducted in 2003: Swedish (85\%) and Greek (84\%) consumers were particularly "concerned" or "very concerned" about the protection of their personal data and privacy while the average at the level of the EU15 member states has been of $60 \%$.

\section{MAIN CHARACTERISTICS OF THE DATA PROTECTION LEGAL ENVIRONMENT}

Research has intended to provide information about major characteristics of the personal data protection legal environment in terms of the specific area of protection, public-private, respectively national-international relationships in the context of the personal data protection and need for national or international laws and regulations.

In terms of the area of protection, consumers have been asked to decide whether the protection should cover their personal data rights as citizens, consumers or both. More than a half of the respondents $(52.1 \%)$ have indicated the rights they have as citizens (as members of their communities) as being more appropriate for protection while other $43.8 \%$ have considered the rights they have as both citizens and consumers. Only a very small part of the sample (less than $5 \%$ ) agreed that protection of their personal data should cover and refer to their consumer rights. Possible explanations of these results can be linked to the limited extent of the experiences the investigated consumers had with direct marketing campaigns conducted in the Romanian market and also to the more frequent 
interactions they had with public entities that are current major holders and users of databases storing personal data.

Relationship between public and private regarding the protection of the personal data brings in the first position, for the majority of the consumers $(47.9 \%)$, the private institutions: almost half of the respondents agreed that personal data protection must be ensured exclusively by private institutions. This may suggest a relative mistrust in the capacity of the public institutions to provide an effective protection of this data. Public institutions (indicated by $27.1 \%$ of the respondents) and mixed (public and private) institutions - indicated by $25.0 \%$ of the respondents hold similar weights and positions that stresses again idea of integrating a private component in the administration of the personal data protection entities. Presence of this private component may also suggest an expectation for a better control over the functioning of the specialized public institutions and can be seen as a guarantee that protection of the personal data will be more effective.

Consumers were asked to indicate which is (are) the most appropriate institution(s) to administrate personal data protection matters. A mixture of institutions - public and private, specialized, less and even not specialized, professional and from other fields of activities - has been presented to the respondents. National Supervisory Authority for Personal Data Processing (NSAPDP) has been mentioned by the majority of respondents as the most appropriate entity to administrate personal data protection; the result expresses not only the appropriateness but also the high degree of awareness of this institution. By comparison, all remaining institutions have been significantly less mentioned.

Table 1: Appropriate institutions to administering personal data protection matters

\begin{tabular}{|c|c|}
\hline Institutions & Percentages \\
\hline National Supervisory Authority for Personal Data Processing & 82.3 \\
\hline General Direction of Persons' Information Administration & 36.5 \\
\hline National Authority for Consumer Protection & 32.3 \\
\hline Association for Consumer Protection & 31.3 \\
\hline Romanian Direct Marketing Association & 16.7 \\
\hline Ministry of Internal Affairs & 7.3 \\
\hline Government of Romania & 7.3 \\
\hline Ombudsman & 6.3 \\
\hline Open Society Foundation & 1.0 \\
\hline Group for Social Dialogue & 1.0 \\
\hline
\end{tabular}

General Direction of Persons' Information Administration of Persons, National Authority for Consumer Protection (formerly known as Office for the Consumer Protection) and the Association for Consumer Protection were the next entities mentioned. Presences of the both public and private consumer protection entities may suggest that from the perspective of consumers, personal data is a component related to their rights as consumers and protection of this data must implemented with the participation of the consumer protection entities. Presence of the General Direction of Persons' Information Administration of Persons should be associated with the important position of the public institutions as owners of personal data in the Romanian market and also with the need for an institutional enforcement of the personal data protection laws.

Romanian Direct Marketing Association has been mentioned by a smaller part of the consumers that may suggest, on a hand, a possible expectation of consumers to see direct marketing professional association more involved in the protection of the personal data and, on another hand, a potential direction of development for the association's future activities.

Ministry of Internal Affairs, the Government of Romania and the Ombudsman held relatively poor positions in this context; until the establishment of the NSAPDP, Ombudsman has been the legal entity designated to administer the personal data protection. Presence of the Ministry of Internal Affairs and of the Romanian Government should be associated with the same need for an institutional enforcement of the personal data protection laws. 
Finally, Open Society Foundation and Group for the Social Dialogue have been mentioned by one percent of the consumers; their peripheral position appears to be normal as these NGOs are involved in other activities than those related to the personal data protection and are well-known in this respect.

Consumers have been asked to assess the need for a personal data protection law. Existence of the law regulating the protection of the personal data has been perceived as "necessary" for $75 \%$ of the respondents while other $21.9 \%$ view the law as "rather necessary". Only a small part of the sample $(3.1 \%)$ has found a specialized protection law as "rather unnecessary" and none of the consumers has seen it as unnecessary. Need for legal framework and the guarantees this framework provides for an effective protection of the personal data may be seen as major motivators of this attitude.

Discussion about the national and/or international character of the personal data protection laws has represented another point of interest in the context of the research. Increased effects of globalization as well as the adhesion of Romania to the European Union are the most important factors bringing into attention this theme. A vast majority of consumers $(86.5 \%)$ have considered that law protecting the personal data should be a European (55.2 $\%)$ and/or international $(31.3 \%)$ one. Less than $15 \%$ of the sample has appreciated that a national law would be enough to cover and solve these aspects. As the Romanian law represents a very close version to the European Directive 95/46/EC, opinions expressed by a part of the sample can reflect a lower level of information regarding the content of the European and Romanian personal data protection law. From a different angle, preference for European/international laws and regulations may be seen as a need for a warranty in terms of the personal data protection effectiveness.

\section{CONTENT OF THE PERSONAL DATA TO BE PROTECTED}

Personal data, according to the Romanian law, refer to "any information referring to a natural person, identified or identifiable; an identifiable person is that person who can be identified, directly or indirectly, particularly with reference to an identification number or to one or more factors specific to details of his physical, physiological, psychological, mental, economical, cultural or social identity".

The law does not make any specification regarding to the content of this data being limited, in this respect, only to the definition of the personal data characteristics - that must be processed fairly and lawfully, collected for specific, explicit and legitimate purposes, adequate, pertinent and not excessive in relation with the processing purposes, and accurate, updated and properly stored.

Law mentions special rules regarding the processing of some special categories of data such as those linked to ethnic and racial origin, political, religious and philosophical opinions or of another (similar) nature, trade-union membership and adhesion, data referring to the state of health or sexual life and data related to the offences and legal contraventions without providing any specification in this respect.

This is obviously one of the weaknesses of the Romanian Personal Data Law and a source of misinterpretations and sometimes even abuses exerted by the law enforcement entity (NSAPDP) and/or the organizations and institutions building, managing and using databases.

Research has intended to provide a general picture of the data that may have a personal character for the consumers and, consequently, should be protected by an improved law. Consumers have received a set of 27 data describing their basic, socio-professional, welfare, social-cultural, communication, identification, health and legal statuses and were asked to indicate those being personal and worthy to be protected by law. Results have shown that:

- $\quad$ in terms of the basic status: first and last name (mentioned by $46.9 \%$ of respondents) is perceived as more personal data while information about gender (16.7\%) and age (16.7 \%) appear as less personal;

- $\quad$ in terms of the socio-professional status: workplace seems to have a more personal character $(45.8 \%)$ while occupation $(32.3 \%)$ and profession $(27.1 \%)$ are less personal; level of education $(10.4 \%)$ is the least personal data in this category; 
- $\quad$ in terms of the welfare status: level of the personal income $(72.9 \%)$ and personal and family's wealth $(69.8 \%)$ are the most personal data for this category and for overall data assessed by consumers; access to different types of household equipment (22.9\%) and services (18.8\%) are perceived as being less personal data in this respect;

- $\quad$ in terms of the social and cultural status: electronic messages of the consumers are the most personal data in this category (59.4\%); political (28.1\%), sexual $(25.0 \%)$ and religious preferences and orientation (22.9 $\%)$ seem to be less personal for the consumers while websites surfed $(16.7 \%)$ and hobbies $(8.3 \%)$ are data perceived as least personal;

- $\quad$ in terms of the communication status: mobile phone (67.7\%) and telephone number $(64.6 \%)$ are the most personal data for the investigated consumers; postal address (38.5\%) and e-mail address (33.3\%) are less personal while the personal website address $(16.7 \%)$ is the least personal data in this category;

- $\quad$ in terms of the identification status: both personal identification number/code $(67.7 \%)$ and the identification documents serial number $(65.6 \%)$ represent data with a relatively high level of personalization;

- $\quad$ in terms of the health and legal statuses: both categories are perceived as being less personal - about $30 \%$ of the consumers considering legal (34.4\%), respectively health status $(27.1 \%)$ in this respect.

Based on these results, a preliminary list of personal data - including data mentioned by at least $40 \%$ or the respondents - to be potentially specified in an improved law of personal data and to be protected through the legal provisions may contain: first and last name, workplace, level of personal income, personal and family wealth, electronic correspondence, mobile phone and telephone numbers, personal identification number/code and ID serial numbers.

Obviously, the above-mentioned list has just an exploratory value as it was obtained at the level of a nonrepresentative sample. Still, the list may suggest that: 1) there is information about consumers that may seem personal from the outside and it is not; 2) there is information that consumers may perceive as being personal although its content may not reveal a high degree of personalization; and 3) asking consumers about what is and what is not personal in terms of the data regarding their characteristics and behavior may lead to a list including items potentially incorporable in a future improved version of the personal data protection law.

\section{CONSUMER PREFERENCES REGARDING THE OPT-IN AND OPT-OUT MECHANISMS}

Two-thirds of the investigated consumers $(65.6 \%)$ have considered that it would be better for them to agree on the collection and processing of their personal data before these operations commence. The opt-in mechanism has been preferred by the respondents confirming this way the inspiration of the lawmakers that have built the Romanian personal data law based on this option. Almost one-third of the respondents $(31.3 \%)$ have preferred to have the opportunity to refuse anytime later to unsubscribe a database and to cease receiving commercial messages.

These results express a rather conservative attitude toward the direct communication (marketing) initiatives in the market that may be explained merely through a certain fear from something rather unknown. Direct marketing campaigns in the Romanian market were not so numerous so far in order to determine a defensive behavior in relationship with the communication instruments based on the use of the personal data. Also, another potential reason of this attitude may be the consumers' lack of trust in the public and/or private entities holding and using their personal data. Opt-in mechanism seems to ensure that only the accepted entities may manage in secure and trustworthy conditions the personal data of the consumers.

\section{KNOWLEDGE ASSOCIATED TO THE LEGAL RIGHTS RELATED TO THE PERSONAL DATA PROTECTION}

Respondents were asked to assess the importance of the rights given by the Law no. 677/2001 regarding the protection of the personal data. An assumption to be investigated has been that not all these rights are important and present interest for the consumers in their quality of owners and providers of personal data. 
Table 2: Importance of the consumers' data processing related rights

\begin{tabular}{|l|c|}
\hline \multicolumn{1}{|c|}{ Consumer rights } & Percentages \\
\hline To object against the data processing & 76.0 \\
\hline To be informed about the data processing & 75.0 \\
\hline To have access to data & 65.6 \\
\hline To refer to a court of law & 60.4 \\
\hline To intervene upon the data & 45.8 \\
\hline To not be subject to an individual decision & 22.9 \\
\hline
\end{tabular}

The right of making objections against the data processing and the right to be informed about the scopes of the data processing are the most important rights granted to consumers, while the right to access the data and the right to refer to a court of law in matters regarding the processing of the personal data have almost a similar high importance. Less important appear to be the rights to intervene upon the data already taken by the databases owners and mostly the right to not be subject to an individual decision in terms of the personal data processing and usage. The poor percentage of this last may be explained through the relative understanding of its content. Based on these results, consumers seem to allocate a higher importance to their rights as providers of personal data, specific action of providing data being consequently more important by comparison to what happens after the data is processed, how this data is managed and later employed by the database owners.

\section{MAJOR RISKS ASSOCIATED WITH THE POOR PERSONAL DATA PROTECTION MECHANISMS}

Poor administration of the personal data may determine negative consequences that affect consumers confidence in the proper functioning of databases and in the direct marketing industry. Several elements of risk have been identified and presented to the respondents in order to be assessed in terms of their importance.

Table 3: Risks perceived by the consumers related to the personal data processing

\begin{tabular}{|l|c|}
\hline \multicolumn{1}{|c|}{ Rights } & Percentages \\
\hline Abuses from the part of private entities & 83.3 \\
\hline Frauds suffered as consumers & 54.2 \\
\hline Increased exposure of their private life & 44.8 \\
\hline Abuses from the part of public entities & 39.6 \\
\hline Limitation of their private space & 24.0 \\
\hline
\end{tabular}

Potential abuses from the part of different private entities appeared to be the most important risk factor for more than $80 \%$ of the respondents while the frauds suffered as consumers have concerned more than a half of the sample. A lower importance has been associated with the increased exposure of the private life, potential abuses from the part of the public entities and the possible limitation of their private space. These results are mostly explained through the relatively low exposure of the investigated consumers to direct marketing campaigns and the reduced employment of the personal data by both public and private entities but as well as trough an unclear identification of their private space content and boundaries.

\section{EXPOSURE TO THE PERSONAL COMMUNICATION MEDIA, PREFERENCES FOR PERSONAL SOURCES OF INFORMATION AND ATTITUDE TOWARD PERSONALIZATION}

Respondents have been asked to express their media preferences in relationship with the search for and receiving commercial information about different products and/or services of interest for them. Both traditional (mass communication) and direct (interactive) media have been considered. 
Although Internet is the most preferred medium for searching and receiving commercial information, and in spite of the good percentage of the snail mail, traditional (mass) communication media seem to hold a more consolidated position at the level of the investigated sample. Television and press are the most preferred media to obtain commercial information. Good results of the radio and outdoor are explainable through the strong increase of the car sales and the number of cars on the roads - radio being listened mainly during driving, respectively to the frequent usage of the outdoor advertising among the communication mix of the companies.

Table 4: Preferences for different traditional and/or direct communication media

\begin{tabular}{|l|c|l|c|}
\hline \multicolumn{2}{|c|}{ Traditional communication } & \multicolumn{2}{c|}{ Direct communication } \\
\hline \multicolumn{1}{|c|}{ Media } & Percentages & \multicolumn{2}{c|}{ Percentages } \\
\hline Television & 67.7 & Internet & 80.2 \\
\hline Press & 58.3 & Mail & 45.8 \\
\hline Radio & 42.7 & Mobile phones & 12.5 \\
\hline Outdoor & 35.4 & Fax & 4.2 \\
\hline \multicolumn{2}{|l}{} & Telephone & 1.0 \\
\hline
\end{tabular}

It is to be noticed that, in terms of the direct communication media, preferences are strongly orientated toward media that allow consumers to keep a safe distance to the organizations sending them direct and personalized messages. Preferences for Internet and classical mail may suggest a rather defensive attitude of the consumers toward the direct communication attempts and express a concern to maintain the control over the communication relationship with the sender organizations.

A somewhat defensive attitude of the respondents has been identified regarding their information search behavior aiming to find and collect the information used as support the decision-making process of buying different products and services. Weight of the consumers preferring rather to search for information than to receive is higher than that of those preferring rather to receive than to search for (and specific percentage is relatively small - $14 \%$ ) suggests a relatively limited penetration of direct marketing and, consequently, a less openness to direct communication attempts conducted in the market.

Figure 1: Information collecting behavior of the consumers

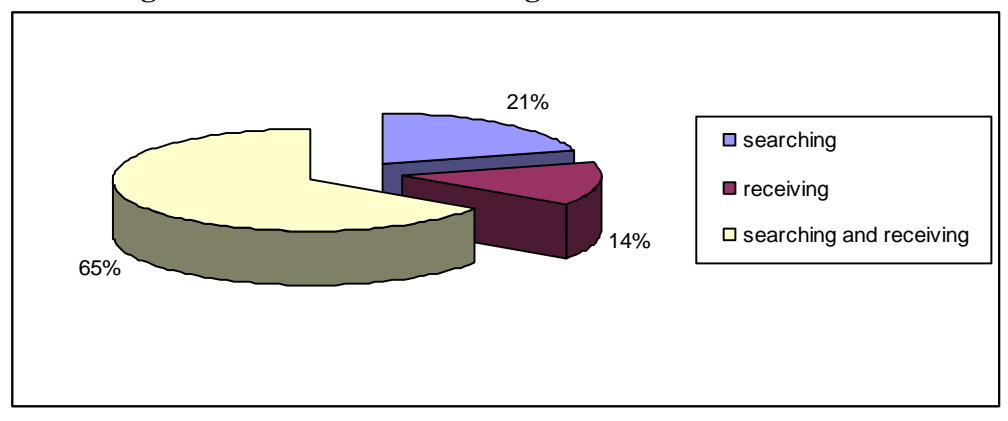

Two-thirds of the sample has been undecided in this respect, preferring both to search for and to receive commercial information about different products and/or services. Reduced exposure to direct marketing campaigns accompanies for this segment of consumers a less formed attitude toward direct marketing tools (as these consumers seem to not be aware of all the benefits and pitfalls of this way of communication). 
One of the most important features of direct marketing, perhaps the key differentiator between the traditional and direct approach, is related to the opportunity to address the consumer in a personal manner. Personalization is also one of the major reasons determining both the increased usage of personal data - in order to improve the communication effectiveness - and the efforts to protect the consumers' private space. Respondents have been asked to express their opinion regarding the importance of personalization for them.

Table 5: Importance of personalization

\begin{tabular}{|l|c|}
\hline \multicolumn{1}{|c|}{ Personalization is: } & Percentages \\
\hline Very important & 9.4 \\
\hline Important & 35.4 \\
\hline Of average importance & 32.3 \\
\hline Less important & 13.5 \\
\hline Not important & 9.4 \\
\hline
\end{tabular}

Opportunity to receive commercial information about different products and services is "important" and "very important" for almost a half of the investigated sample while for one-third of consumers this possibility presents an average importance. Strong presence of the traditional communication media, relatively limited development of the direct marketing industry as well as the risks perceived in relationship with the direct marketing efforts may be among the most relevant factors determining this attitude.

Results provided by the research in terms of the consumers' exposure to the personal communication media, preferences for personal sources of information and attitude toward personalization show that personal data protection is a matter to be approached and solved rather later. Although personalization is important and very important for a significant segment of consumers, their effective behavior - expressed by the ways used to get commercial information and the preferences for different media as sources of information - reveals that a higher degree of risk and, consequently, an increase in the need for an effective personal data protection will be noticeable in the near future.

\section{DEVELOPMENT AND IMPLEMENTATION A ROBINSON LIST}

Implementation of the Robinson List is a recent initiative (April 2007) developed in the Romanian market as a response of the direct marketing industry to the increasingly involvement of NSAPDP (not always backed by good intentions...) to control the databases building and employment and the overall activities of the data controllers. Inspired by the experiences in the well-developed markets where similar instruments work effectively and ensure a reasonable protection of the personal data and private space of consumers, Romanian Direct Marketing Association has initiated the opening of the Romanian Robinson list. Investigated consumers have been asked to answer how necessary is for them the existence of a list (database) where they could subscribe in order to avoid/stop receiving commercial messages and if they would intend to subscribe a list of this type.

Figure 2: Robinson List existence

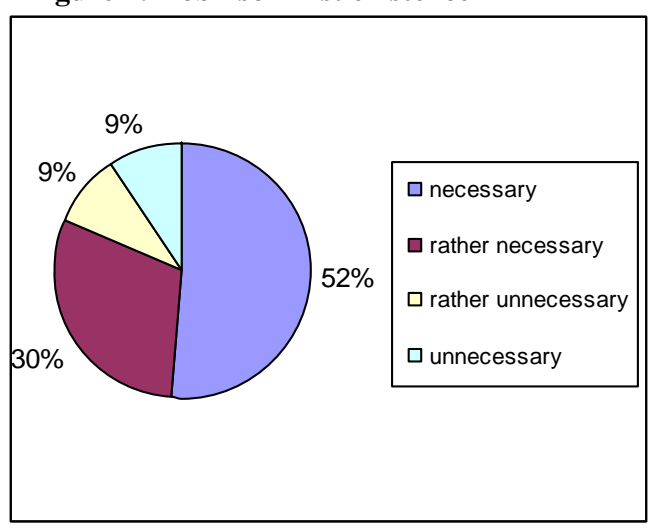

Figure 3: Intentions to join the Robinson List

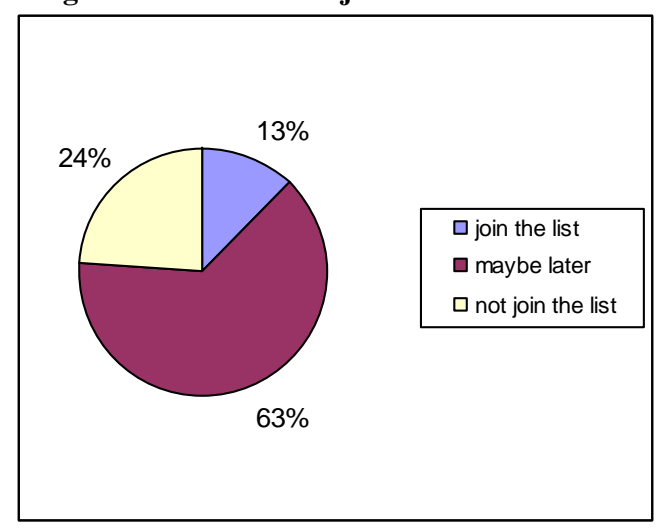


More than $80 \%$ of the respondents have considered that existence of a Robinson List is "necessary" or "rather necessary". This result is relatively similar with that expressing the necessity to have a dedicated law regulating the personal data status and processing and it can be seen as an expression of a need for a legal protection and a protected environment in this respect.

As about subscribing Robinson list, only $13 \%$ of the investigated consumers would "join immediately" the list while $24 \%$ would "definitely not do it". Almost two-thirds of the consumers have adopted an undecided attitude toward the Robinson list. Lack of a firm position in this respect can be explained through the low level of knowledge associated with the content and functioning of this instrument. The current positive difference between consumers not joining the list and, respectively, those planning to do so may be seen as favorable sign for the potential development of the direct marketing industry in Romania.

\section{CONCLUSIONS}

Although an exploratory attempt, the research has led to several conclusions that may serve as basis for future more in-depth research in the field.

The most important one refers to the meaning of the personal data. Definitely, the content of the data with "personal" significance for the consumers is so far under discussion. With the exception of some general provisions made in the European and/or international directive, guidelines, conventions, codes of conduct and any other similar documents regarding protection for data of a "sensitive nature" - religion, political beliefs, genetics or medical information - and the personal identification numbers and/or codes, personal data are still to be defined. Absence of a proper definition, adapted to the demographical, economical, technological, cultural and political changes occurred in the market may lead to: 1) an unfavorable attitude of the consumers toward the uses of this data affecting not only the direct marketing industry but the entire marketing activity conducted by the organizations; 2) abuses of the companies and organizations holding and using personal data in direct communication (marketing) campaigns and 3) abuses of the public authorities and institutions responsible for the enforcement of the personal data protection law.

Results of the research suggest that a potential involvement of the private entities should be considered in order to create the effective legal framework for the protection of the personal data and to transpose it into practice. This involvement may mean participation, through the authorized representatives and/or institutions, at the creation of the personal data protection environment and exertion of a control over its functioning. Public authorities and institutions should encourage, support and implement all good private initiatives leading to a better protection of the personal data.

Voice of the consumers must be taken into consideration in the process of developing an effective regulatory environment in this field. If is to be understood that contribution of all the actors involved is expected companies conducting direct marketing campaigns, providers of specialized direct marketing services, public institutions regulating the direct marketing and overall business and economic activity, and last but not the least the consumers - than it is also to be accepted that only initiatives based on opinions, attitudes and expectations of the consumers may lead to an efficient personal data protection. The major risk to be faced in the absence of a consumer-provided data protection background is represented by the creation of a mechanism that will not work due to its bureaucracy, lack of flexibility and higher costs.

\section{End Notes}

1. A good starting point can be found in the definition proposed by Ferdinand D. Schoeman (1984) and quoted by András Jóri stating that privacy can be regarded as a "claim, entitlement or right of an individual to determine what information about himself (or herself) may be communicated to others; the measure of control an individual has over information about himself, intimacies of personal identity, or who has sensory access to him; and a state or condition of limited access to a person, information about him, intimacies of personal identity". Next step should the identification of the specific characteristics of privacy that will become the personal data to be protected by dedicated laws. 
2. A questionnaire including twenty questions has been employed to collect data at a level of sample of urban consumers aged 18 to 45 with average and higher education. Total number of questionnaires has been of 133 from which, after the validation procedures (involving the elimination from processing of the incomplete or filled-in with errors), a number of 96 have been processed. Results have been focused on the descriptive results in terms of the research objectives without to be conducted a socio-demographical analysis.

\section{REFERENCES}

1. Bergkamp, Lucas, EU Data Protection Policy. The Privacy Fallacy: Adverse Effects of Europe's Data Protection Policy In An Information-Driven Economy, Computer Law\&Security Report Vol.18, no.1, 2002, p.31-47

2. Godin, Seth, Permission Marketing: Turning Strangers into Friends and Friends into Customers, Simon and Schuster, New York, 1999

3. Hustinx, Peter J., Data Protection at Crossroads, $8^{\text {th }}$ Symposium on Privacy and Security, Zürich, 22 October 2003

4. Jóri, András, Data Protection Law - An Introduction, http://www.dataprotection.eu/, 2006-2007

5. Safell, Jack, Personal Data Protection Law and Direct Marketing in the EU: Comparisons and Comments, RoDirect 2007, Second International Direct Marketing Conference, Bucharest, 19-20 April 2007

6. Smith, H. Jeff, Milberg, Sandra J., Burke, Sandra J., Information Privacy: Measuring Individuals' Concerns about Organizational Practices, MIS Quarterly, Vol.20, No. 2, June 1996, p.167-196

7. Stephens, David O., Data Protection in Europe, ARMA Records Management Quarterly, Vol.32, no.4, October 1998

8. Stone, Bob, Jacobs, Ron, Successful Direct Marketing Methods, $7^{\text {th }}$, McGraw-Hill, New York, 2001

9. Taylor, Curtis R., Consumer Privacy and the Market for Customer Information, The Rand Journal of Economics, Vol. 35, no. 4, Winter 2004, p.631-650

10. Directive 95/46/EC of the European Parliament and of the Council of 24 October 1995 on the protection of individuals with regard to the processing of personal data and on the free movement of such data, http://ec.europa.eu/justice home/fsj/privacy/docs/95-46-ce/dir1995-46_part1_en.pdf,

11. http://ec.europa.eu/justice home/fsj/privacy/docs/95-46-ce/dir1995-46_part2 en.pdf

12. European Union citizens' views about privacy, Special EuroBarometer 196: Data Protection, December 2003,

13. http://ec.europa.eu/public_opinion/archives/ebs/ebs_196_data_protection.pdf

14. Law no.677/2001 for the Protection of persons concerning the processing of personal data and free circulation of such data, www.dataprotection.ro/images/PDF/Law_677en.pdf

15. Privacy and Personal Data Protection, Organization for Economic Co-operation and Development,www.oecd.org/sti/security-privacy, 2007

16. Privacy versus Information, http://www.coe.int/t/e/legal_affairs/legal_cooperation/data protection/background/2Presentation.asp\#TopOf Page, 2007

17. The Organization for Economic and Co-operation Guidelines on the Protection of Privacy and Transborder Flows of Personal Data, http://www.oecd.org/document/18/0,2340,en_2649_34255_1815186_1_1_1_1,00.html 
NOTES 